\title{
The influence of Schweres Warmblut breed stallions on the exterior of Silesian breed horses
}

\author{
E. Walkowicz', O. Unold ${ }^{2,3}$, H. Maciejewski and P. Skrobanek ${ }^{2}$ \\ ${ }^{1}$ Wroclaw University of Environmental and Life Sciences, Department of Horse Breeding and Riding, \\ Kożuchowska 6, 51-631 Wrocław, Poland \\ ${ }^{2}$ Wroclaw University of Technology, Institute of Computer, Engineering, Control and Robotics \\ Wybrzeże Wyspiańskiego 27, 50-370 Wrocław, Poland
}

KEY WORDS: horses, Silesian breed, breeding, selection, measurements

Received: 08 February 2012

Revised: 07 June 2013

Accepted: 2 September 2013

${ }^{3}$ Corresponding author: e-mail: olgierd.unold@pwr.wroc.pl
ABSTRACT. The objective of this study was to analyse the influence of introducing Schweres Warmblut (SchW) blood on the zoometric features of Silesian breed horses. The research material was pure Silesian breed horses and crossbreeds with the SchW breed, born in the period of 1984-2004. The population was divided into four groups, depending on the contribution of Schweres Warmblut blood (0.0\%, 0.1-24.9\%, $25.0-49.9 \%$ and $50 \%$ and more). Differences were determined among groups in the range of values of the three basic characteristics (height at withers, chest and cannon circumferences), build indices (massiveness, boniness and strength), and point-scale estimation. The highest differences between Silesian horses and $F_{1}$ generation crossbreeds were observed in height at withers (stallions: 161.04 and $165.13 \mathrm{~cm}$, mares: 159.58 and $162.45 \mathrm{~cm}$ ), massiveness index (stallions:124.56 and 120.19), and point-scale estimation (mares: 77.0 and 79.61 points, respectively). The groups with lower shares of SchW blood were characterized by intermediate values that corresponded more to changes that took place in the Silesian breed over time, than to those resulting from the contribution of SchW blood.

\section{Introduction}

The Silesian breed belongs to the group of heavy warmblood horses, represented in Europe by German Oldenburg and East-Friesian horses, Dutch Gelderlanders, and Danish Groningen horses (Sprenger, 1994; Takens, 1995; Van Lijsel, 2010). This type, originating from medieval harddrivers, was intended for quick transport, and with time was transformed into artillery and agricultural horses. The Silesian breed was created at the turn of the 19th and 20th centuries, in the area of Upper and Lower Silesia via crossing of native mares with Oldenburg and East-Friesian stallions. It was characterised by high carriage strength, good movement in walk and trot, and a gentle, balanced character. By the Second World War, a few meaningful male lines of differentiated dimensions and utility values were formed in the Silesian breed (Bruse, 1942). Mating in moderate consanguinity and in breed on remarkable ancestors led to the formation of male lines with high utility value transferred onto the progeny. After the war, the breeding of Silesian and Oldenburg horses was conducted independently. In Germany, the Oldenburg breed was almost extinct and was reconstructed in the 1980s from a sparse group of surviving stallions 
(Schweres Warmblut, 2003, 2008). In Poland, the demand for work horses was maintained for a longer time, nonetheless, in the 1970s, they were graded considerably with Thoroughbred blood in order to create saddle horses for heavier riders.

In the 1980s, interest in horses of the Silesian breed increased nationwide, especially in the regions of Malopolska and Lubelszczyzna, where they had to create a buffer zone to prevent the introduction of coldblood horses that were being imported in order to improve the meatiness of the local population (Walkowicz, 1995). Moreover, it was decided to develop the Silesian breed in two directions: continuation of the type heavy carriage horse, and towards formation of a sports horse for carriage and dressage sports. It was therefore decided to use Oldenburg sires of the old type as progenitors in the Silesian breed. An additional stimulus for such a decision was the perspective of profitable exports of horses to Germany as breeding material (Jodkowska et al., 1999).

Two stallions from the then German Democratic Republic were in stud farm Strzelce Opolskie, and Enzian 1424, used in 1983-1987 in stud farm Strzegom. In 1985-1986, the stallions Glockner Mo 1433 and Eidam Mo 1426 were imported and were used until 1990. In 1997 the stallion, Evento Mo 2502, was purchased, and in 1999, Eliot 803/ Wł. These stallions were to 'refresh' Silesian horse blood with the old type, and were widely used in breeding, significantly influencing the Silesian breed population, with what later appeared not to necessarily be a favourable effect (Walkowicz, 2000). Taking into consideration that in the postwar period the Oldenburg breed was also the subject of transformation, especially by grading with Thoroughbred stallions, those horses considerably diverged from the primary archer and are presently referred to as Schweres Warmblut (SchW; Heavy Warmblood Horse), which was not entirely taken into consideration in Polish breeding, where the name 'Oldenburg in the old type' was consistently maintained (this is the way in which the imported sires were recorded in Polish Stud Books). After the year 2000, these opinions were verified, accepting the dissimilarity of the SchW breed, and in the year 2007 the decision to discontinue using that breed of sires in breeding Silesian horses was made (Silesian horses may still be used in breeding SchW). The aim of the study to analyse the effects of SchW breed sires used in breeding Silesian horses and their influence on the breed's exterior features.

\section{Material and methods}

The research material was Silesian breed horses, born in the period of 1984-2004, sourced from state and private breeders. The information for the study was collected from the databases of Local Horse Breeding Associations (years 1984-2000) and the Polish Horse Breeding Association (years 2001-2004). The horses were divided according to sex, year of birth, and contribution of SchW blood in their pedigree.

Four breed groups were delineated, depending on the contribution of Schweres Warmblut breed blood:

- Silesian - without the contribution of SchW blood,

- SchW 1 - crossbreeds with a contribution of $50 \%$ and more of SchW blood,

- SchW 2 - crossbreeds with a contribution of 25$49 \%$ SchW blood,

- SchW 3 - crossbreeds with a contribution of less than $25 \%$ SchW blood.

The assignment to the SchW group was based on the summary contribution of blood in a five-generation pedigree.

On the basis of the year of birth, the population was divided into four groups:

I - born in the period 1984-1989,

II - born in the period 1990-1994,

III - born in the period 1995-1999,

IV - born in the period 2000-2004.

Basic zoometric parameters of the examined horses were analysed, i.e. height at withers, chest circumference, cannon circumference, and built indices, calculated according to the formulae:

- massiveness index $=$ (chest circumference/ height at withers) $\times 100$,

- boniness index $=($ cannon circumference $/$ height at withers $) \times 100$,

- strength index (Baron's) $=$ (chest circumference ${ }^{2} /$ height at withers) $\times 100$.

The analysis of exterior features was based on point-scale estimation (on a one-hundred-point scale). The following elements were taken into consideration: - point-scale estimation: sum of estimation points (max. 100 pts),

- build: sum of points for head and neck, trunk, type and overall appearance (max. $50 \mathrm{pts}$ ),

- foundation: sum of points for limbs, hoofs and movement (max. $50 \mathrm{pts}$ ),

Additionally distinguished features of the highest ratings span:

- type: conformity with breed type (max. 15 pts), appearance: structural harmony and presentation (max. 15 pts),

- movement: sum of points for walk and trot (max. $20 \mathrm{pts})$. 
Table 1. Mean values of zoometric parameters of Silesian mares with various share of SchW blood

\begin{tabular}{lrllllll}
\hline Group & $\mathrm{n}$ & $\begin{array}{l}\text { Height } \\
\text { at withers, } \\
\mathrm{cm}\end{array}$ & $\begin{array}{l}\text { Chest } \\
\text { circumference, } \\
\mathrm{cm}\end{array}$ & $\begin{array}{l}\text { Cannon } \\
\text { circumference, } \\
\mathrm{cm}\end{array}$ & $\begin{array}{l}\text { Massiveness } \\
\text { index }\end{array}$ & $\begin{array}{l}\text { Boniness } \\
\text { index }\end{array}$ & $\begin{array}{l}\text { Strength } \\
\text { index }\end{array}$ \\
\hline Silesian & 2213 & $159.58^{\text {abc }}$ & $196.75^{\text {ab }}$ & $22.15^{\text {abc }}$ & $123.27^{\text {ab }}$ & $13.88^{\text {a }}$ & $242.88^{\text {ab }}$ \\
SchW 1 & 112 & $162.45^{\mathrm{c}}$ & $199.87^{\text {bd }}$ & $22.42^{\mathrm{c}}$ & $123.00^{\text {de }}$ & 13.80 & $246.18^{\text {bd }}$ \\
SchW 2 & 362 & $162.30^{\text {bd }}$ & $196.23^{\text {cd }}$ & $22.36^{\text {bd }}$ & $120.89^{\text {bcde }}$ & $13.78^{\text {b }}$ & $237.52^{\text {acd }}$ \\
SchW 3 & 241 & $163.13^{\text {ad }}$ & $198.93^{\text {ac }}$ & $22.53^{\text {ad }}$ & $121.93^{\text {ac }}$ & 13.81 & $242.99^{c}$ \\
In total & 2928 & 160.32 & 196.98 & 22.22 & 122.86 & 13.86 & 242.36 \\
\hline
\end{tabular}

a...e - means marked with different letters differ significantly $(p<0.05)$

Table 2. Mean values of zoometric parameters of Silesian stallions with various share of SchW blood

\begin{tabular}{lrllllll}
\hline Group & $\mathrm{n}$ & $\begin{array}{l}\text { Height } \\
\text { at withers, } \\
\mathrm{cm}\end{array}$ & $\begin{array}{l}\text { Chest } \\
\text { circumference, } \\
\mathrm{cm}\end{array}$ & $\begin{array}{l}\text { Cannon } \\
\text { circumference, } \\
\mathrm{cm}\end{array}$ & $\begin{array}{l}\text { Massiveness } \\
\text { index }\end{array}$ & $\begin{array}{l}\text { Boniness } \\
\text { index }\end{array}$ & $\begin{array}{l}\text { Strength } \\
\text { index }\end{array}$ \\
\hline Silesian & 488 & $161.04^{\text {abc }}$ & $200.61^{\text {abc }}$ & $23.22^{\text {ab }}$ & $124.56^{\text {abc }}$ & $14.42^{\text {abc }}$ & $258.18^{\text {abc }}$ \\
SchW 1 & 111 & $165.13^{\text {cef }}$ & $198.5^{\mathrm{c}}$ & $23.43^{\text {bd }}$ & $120.19^{\text {ce }}$ & $14.19^{\mathrm{c}}$ & $238.89^{\text {ce }}$ \\
SchW 2 & 170 & $163.60^{\text {bdf }}$ & $198.20^{\mathrm{b}}$ & $23.26^{\mathrm{c}}$ & $121.15^{\text {bd }}$ & $14.22^{\mathrm{b}}$ & $240.35^{\text {bd }}$ \\
SchW 3 & 504 & $161.94^{\text {ade }}$ & $198.34^{\mathrm{a}}$ & $23.09^{\text {acd }}$ & $122.46^{\text {ade }}$ & $14.26^{\mathrm{a}}$ & $243.27^{\text {ade }}$ \\
In total & 1273 & 162.09 & 199.20 & 23.19 & 122.89 & 14.31 & 245.15 \\
\hline
\end{tabular}

a.... - means marked with different letters differ significantly $(p<0.05)$

Table 3. Point-scale estimation of mares with various share of SchW blood

\begin{tabular}{|c|c|c|c|c|c|c|c|}
\hline Group & $\mathrm{n}$ & $\begin{array}{l}\text { Point-scale } \\
\text { estimation, pts }\end{array}$ & $\begin{array}{l}\text { Build, } \\
\text { pts }\end{array}$ & $\begin{array}{l}\text { Foundation, } \\
\text { pts }\end{array}$ & $\begin{array}{l}\text { Type, } \\
\text { pts }\end{array}$ & $\begin{array}{l}\text { Appearance, } \\
\text { pts }\end{array}$ & $\begin{array}{l}\text { Movement, } \\
\text { pts }\end{array}$ \\
\hline Silesian & 2135 & $77.00^{\mathrm{abc}}$ & $30.69^{a b c}$ & $32.79^{a b c}$ & $13.48^{\mathrm{abc}}$ & $13.49^{a b c}$ & $13.50^{\mathrm{abc}}$ \\
\hline SchW 1 & 109 & $79.61^{\text {cde }}$ & $31.49^{\text {cde }}$ & $34.33^{\text {cef }}$ & $13.84^{\mathrm{cd}}$ & $13.74^{c}$ & $14.58^{\text {cef }}$ \\
\hline SchW 2 & 242 & $78.12^{\text {be }}$ & $31.25^{\text {be }}$ & $33.21^{\mathrm{bdf}}$ & $13.71^{\mathrm{bd}}$ & $13.69^{b}$ & $13.85^{\text {bdf }}$ \\
\hline SchW 3 & 349 & $78.32^{\mathrm{ad}}$ & $32.22^{\mathrm{ad}}$ & $33.45^{\text {ade }}$ & $13.77^{\mathrm{a}}$ & $13.64^{a}$ & $13.97^{\text {ade }}$ \\
\hline In total & 2917 & 77.35 & 30.84 & 32.96 & 13.55 & 13.54 & 13.62 \\
\hline
\end{tabular}

a...f - means marked with different letters differ significantly $(p<0.05)$

Table 4. Points-scale estimation of stallions with various share of SchW blood

\begin{tabular}{lrllllll}
\hline Group & $\mathrm{n}$ & $\begin{array}{l}\text { Point-scale } \\
\text { estimation, } \\
\text { pts }\end{array}$ & $\begin{array}{l}\text { Build, } \\
\text { pts }\end{array}$ & $\begin{array}{l}\text { Foundation, } \\
\text { pts }\end{array}$ & $\begin{array}{l}\text { Type, } \\
\text { pts }\end{array}$ & $\begin{array}{l}\text { Appearance, } \\
\text { pts }\end{array}$ & $\begin{array}{l}\text { Movement, } \\
\text { pts }\end{array}$ \\
\hline Silesian & 459 & $78.74^{\text {abc }}$ & $31.27^{\text {ab }}$ & $33.89^{\mathrm{a}}$ & $13.74^{\mathrm{ab}}$ & $13.59^{\mathrm{ab}}$ & $14.07^{\mathrm{a}}$ \\
SchW 1 & 95 & $79.30^{\mathrm{c}}$ & $31.24^{\text {cd }}$ & $34.40^{\mathrm{abc}}$ & $13.72^{\mathrm{c}}$ & $13.67^{\mathrm{de}}$ & $14.47^{\mathrm{abc}}$ \\
SchW 2 & 120 & 79.34 & $31.60^{\text {bd }}$ & $33.85^{\mathrm{c}}$ & $3.88^{\mathrm{bc}}$ & $13.99^{\text {bce }}$ & $14.12^{\mathrm{c}}$ \\
SchW 3 & 451 & $79.31^{\mathrm{a}}$ & $31.47^{\mathrm{ac}}$ & $33.98^{\mathrm{b}}$ & $13.82^{\mathrm{a}}$ & $13.80^{\text {acd }}$ & $14.08^{\mathrm{b}}$ \\
In total & 1125 & 79.09 & 31.38 & 33.97 & 13.79 & 13.71 & 14.11 \\
\hline
\end{tabular}

a.... - means marked with different letters differ significantly $(p<0.05)$

The basic descriptive statistics of the analysed features are presented in Tables 1-4. The effect of the contribution of Schweres Warmblut blood on zoometric features and point-scale estimates was assessed using the ANOVA test, where the significance of pair-wise differences between groups (e.g., Silesian vs $\mathrm{SchW} 1, \mathrm{SchW} 1$ vs SchW 2, etc.) was calculated using Tukey's test (the calculations were conducted using the SAS/ STAT system) (Sobczyk, 2008; Łomnicki, 2010).

\section{Results}

The mean height at withers in purely Silesian mares was $159.6 \mathrm{~cm}$, while in the case of crossbreed mares, this value ranged from 162.30 to $163.13 \mathrm{~cm}$ (Table 1). It is noteworthy that in the SchW 1 group, represented mainly by the progeny of SchW stallions, the highest values of chest circumference were noted along with high massiveness and strength indexes, while in group SchW 2, these values were lower than in group SchW 3, with the lowest share of SchW blood. 
In the stallion population, the SchW 1 group was characterized by the highest height at withers, i.e. (mainly) progeny of crossbreeds after SchW sires and this height decreased with decreasing share of SchW blood (Table 2). Concurrently, the reverse tendency was noted in the range of massiveness and strength indexes, which is understandable given their correlation with the value of height at withers.

Analysis of the detailed point-scale estimation of mares revealed that in all of the features analysed, the highest score was obtained by horses from the SchW 1 group, while the lowest, by pure Silesian horses (Table 3). The groups SchW 2 and SchW 3 obtained intermediate values that did not differ significantly. The least differentiated was the assessment for appearance; the differences among the crossbreeds were on the level of hundredth parts of a point.

Similar results were obtained when comparing point-scale estimations of stallions (Table 4). It should be noted, however, that they were characterized by considerably less differentiated scores among particular groups, when compared with mares. The range of scores in each of the analysed features was less than 1 point, which indicates sharper selection and greater population equalization.

When analysing the differentiation of zoometric parameters over a span of years it became apparent that they were subject to a significant degree of change, which is presented on the example of height at withers (Figure 1). In the initial period, the differences between pure Silesian horses and crossbreeds with SchW blood were nearly $2 \mathrm{~cm}$ in stallions and $3 \mathrm{~cm}$ in mares, while in subsequent years, with the systematic increase in height at withers in the whole population, these differences decreased.

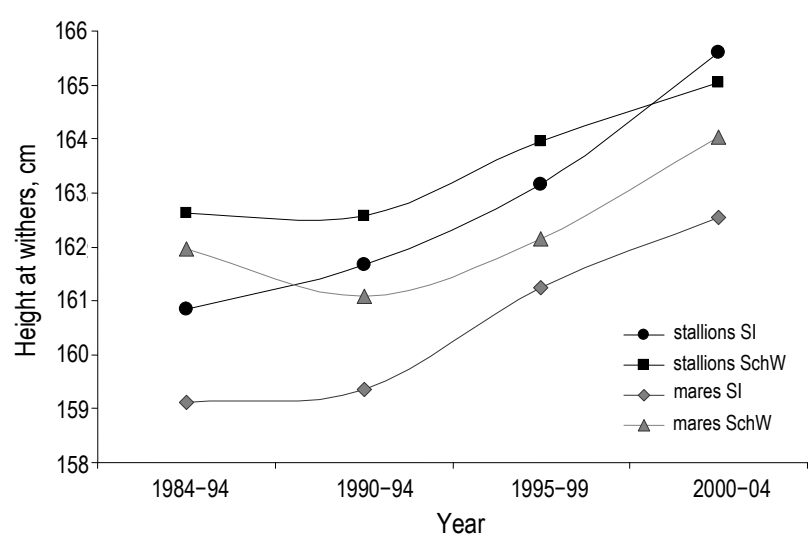

Figure 1. Changes in height at withers of pure Silesian horses and those with different share of SchW blood, within the years (SI - pure Silesian; SchW - Silesian with SchW)
In the years 2000-2004, pure Silesian stallions exceeded in height the crossbreds with SchW blood (Walkowicz et al., 2011). It should, however be emphasized, that in the years 1984-1989, only two groups of horses were present in the breeding: pure Silesian and the first generation after SchW sires; with passing years, the number of crossbreeds increased, but they were mainly individuals of a smaller SchW blood share.

\section{Discussion}

Enrichment of the gene pool of a breed via blood refreshing and cross breeding is often practiced in horse breeding, however, the real genetic distance between the populations should be taken into consideration (Wilkens, 2005; Hamann and Distl, 2008; Hellsten et al., 2009). It can be concluded from the studies of Eckert et al. (1995) and Cholewiński et al. (1998) that among all breeds originating from Oldenburg and East-Friesian horses, the highest similarity is observed between Saxonian and Silesian horses. It should, nonetheless, be mentioned that these studies dealt with a period in Polish breeding following nearly ten years of using SchW horses (Walkowicz et al., 1995) during which the contribution of SchW blood was not marked as introduction of foreign blood. As demonstrated in the study of Ząbek et al. (2003), these breeds differed in terms of both genotype and phenotype. Despite their common origin, the differences appeared to be so large, that their mating was, in practice, inter-breed crossing.

The influence of the SchW breed was seen as a significant effect on the crossbreeds' exterior, which was visible especially in the range of basic characteristics and their indices. The horses with a share of SchW blood that was higher than in pure Silesians were also characterized by a slightly higher cannon circumference and lower massiveness index. With passing years, this difference decreased, since the height at withers in pure Silesian horses increased, which was related to the introduction of a breeding plan for the transformation of part of the Silesian breed into a modern sports horse and the consequent selection with respect to height at withers and lower massiveness. On comparing the values of zoometric features depending on the contribution of SchW blood in the pedigree (corresponding to subsequent filial generations) it can be noticed that with time, the differences are decreasing (Walkowicz et al., 2011). This is understandable given that after mass utilization of four sires during the first five years, the subsequent ten years was only mating of their progeny with each other, thus the group of horses with a high 
share of SchW blood was gradually decreasing. The next stallions, imported at the end of the 1990s, were used on a considerably smaller scale. Moreover, considerable exterior changes within the Silesian breed occurred in the meantime as a result of implementation of the plan to create a modern sports horse, which reduced the differences between Silesian horses and newly imported SchW stallions. It may be thus concluded that the same effect of population grading would have been obtained entirely by breeding work within the Silesian breed, without the contribution of the SchW breed.

The idea of using SchW stallions in breeding Silesian horses was reasonably justified, particularly because of the small populations of both breeds, which constituted a significant breeding risk. Moreover, there were real perspectives of international cooperation aimed at preservation of breeds in the heavy warmblood horse type originating from old Oldenburg horses (Takens, 1995; Jodkowska et al., 1999). The soundness of this decision is also supported by the fact that most of the SchW sires established their own genealogical lines in Poland from which a large number of valuable progeny originated (own studies, unpublished). Nevertheless, poor selection appeared to be a problem of Polish breeding, resulting in numerous crossbreeds not fulfilling current breeding criteria having been used for reproduction (Walkowicz, 2000). Also, an insufficiently precise breeding plan had an unfavourable influence, as it did not assure the maintenance of a suitable percentage of horses of pure Silesian pedigree as a genetic reserve of the breed (Programme 2007). Finally, crossbreeds with SchW blood had to be included into the programme of preservation of the genetic resources of the Silesian breed, started in 2004-2005, despite the SchW breed having been excluded from Silesian breeding. Concurrently, the programme of the SchW breed still allows the use of Silesian horses as breeding material.

\section{Conclusions}

The history of the Silesian breed may be an example of how much care is required in modification of breeding programmes, especially when they involve introduction of foreign breed individuals into the gene pool. In order to obtain positive results, it is necessary to precisely determine the range of changes introduced and elaboration of strict selection criteria for crossbreeds, retaining only the most valuable individuals for breeding. In addition, it is also necessary to maintain a suitable genetic reserve of the original breed by selection of breeding material and definitively excluding feature improvement via crossing.

\section{References}

Bruse H.G., 1942. Die Blutlinien des Schweren Schlesischen Warmblutpferdes. Dtsch. Warmblut H 10. Mitteilungen des Instituts fur Tierzucht und Milchwirtschaft der Universitat Breslau, 8

Cholewiński G., Cothran E.G., Walkowicz E., 1998. Genetic analysis of major sire lines within the Silesian horse breed from Poland. Anim. Genet. 29, Suppl. 1, 16

Eckert A., Cholewiński G., Erhardt G., 1995. Genetic structure of AltOldenburger and Ostfriesen breeds in Europe. International Conference 'Perspectives of Regional Breeds Horses Breeding. Silesian Breed Horses', pp. 25-32

Hamann H., Distl O., 2008. Genetic variability in Hanoverian warmblood horses using pedigree analysis. J. Anim. Sci. 86, 1503-1513

Hellsten E.T., Näsholm A., Jorjani H., Strandberg E., Philipsson J., 2009. Influence of foreign stallions on the Swedish Warmblood breed and its genetic evaluation. Livest. Sci. 121, 207-214

Jodkowska E., Walkowicz E., Geringer H., 1999. The overall performance and prospects of use Silesian stallions from Książ Depot in European breeding scheme of heavy warmblood horses. In: Proceedings of $50^{\text {th }}$ EAAP Annual Meeting, Zurich, p. 339

Łomnicki A., 2010. Introduction to Statistics for Life Science. (in Polish). PWN Warszawa

Programme. 2007. Programme of Silesian Breed Horses Breeding (in Polish). PZHK, Warszawa

Schweres Warmblut. Das Hengstbuch, 2003. Verlag Sachsens Pferde $\mathrm{GmbH}$, Moritzburg

Schweres Warmblut. Das Hengstbuch 1, 2008. Erganzungsband. Verlag Sachsens Pferde $\mathrm{GmbH}$, Moritzburg

Sobczyk M., 2008. Statistics (in Polish). PWN, Warszawa

Sprenger K.-U., 1994. The German Coach Horse 'Saxony Warmblood'. Anim. Genet. Resours. Inform. 14, $99-105$, DOI http://dx.doi. org/10.1017/S1014233900000389

Takens E., 1995. Groninger Horse in the Netherlands. In: Proceedings of International Conference: 'Perspectives of Regional Breeds Horses Breeding. Silesian Breed Horses', pp. 65-69

Van Lijsel A., 2010. Revolution in horse breeding. The Gelderlander http://www.gelderlanderhorse.nl/english/revolution.htm. Accesed Dezember 2010

Walkowicz E., 1995. Present situation and prospect of the Silesian horse breeding (in Polish). In: Proceedings of International Conference: Prospect of the regional horse breeding. Silesian horse. Wrockaw (Poland), pp. 17-24

Walkowicz E., 2000. The effect of crossing of Silesian breed with Thoroughbred and halfbred horses. (in Polish). Zesz. nauk. AR Szczecin, Zoot. 40, 277-284

Walkowicz E., Praska U., Małysz W., 1995. Influence of alien breed on biometrical parameters of the Silesian Mares. (in Polish). In: Proceedings of International Conference: Prospect of the regional horse breeding. Silesian horse. Wrocław (Poland),Conference Materials, pp. 45-48 
Walkowicz E., Unold O., Maciejewski H., Skrobanek P., 2011. Zoometric indices in Silesian Horses in the years 1945-2005. Ann. Anim. Sci. 11, 557-567

Wilkens J., 2005. Reasons and Effects of Using Thoroughbreds in a Warmblood Breed to Improve Dressage and Jumping Marelines. The American Hanoverian. Society Inc., Lexington (USA)
Zabek T., Duniec M., Bugno M., 2003. Genetic relationships between Silesian, Thoroughbred and Oldenburg horses based on DNA microsatellite polymorphism. Ann. Anim. Sci. 3, 213-224 